\title{
Use of railway wheel wear and damage predictions tools to improve maintenance efficiency through the use of Economic Tyre Turning (ETT)
}

\author{
Yousif Muhamedsalih ${ }^{1 *}$, Julian Stow ${ }^{1}$ and Adam Bevan ${ }^{1}$ \\ 1 Institute of Railway Research, University of Huddersfield, Huddersfield HD1 3DH, UK \\ - y.muhmedsalih@hud.ac.uk
}

\begin{abstract}
This paper investigates the wear rate and pattern for wheels turned with thin flanges using Economic Tyre turning (ETT). ETT refers to the process of turning wheels to a profile that has the same tread shape but a thinner flange than the design case profile, allowing less material to be removed from the wheel diameter during re-profiling. Modern wheel lathes are typically capable of turning such profiles but GB railway group standards do not currently permit their use.

The paper demonstrates how the Wheel Profile Damage Model (WPDM) [1] can be used, with a good degree of accuracy, to predict both the magnitude of wheel wear and the worn profile shape of the design and ETT re-profiled wheels for service mileages exceeding 100,000 miles. The WPDM simulations were run for two typical Electric Multiple Units (EMU) (one suburban and one inter-city train fleet) and a 2-axle freight wagon.
\end{abstract}

Additionally, it discusses the calibration methodology used to adjust the wear coefficients contained within the Archard wear model to improve the accuracy of the WPDM simulation results for specific routes and vehicle types. Furthermore, this paper presents the findings of a trial of ETT on a fleet of inter-city trains.

The analysis is extended to predict the effect of using ETT on rail RCF for typical routes and operating conditions using a series of vehicle dynamic simulations. The analysis considers new 56E1 and 60E2 rails together with a selection of worn wheel.

The research provides valuable evidence to support a future change to the standards which will allow train operators/maintainers to implement ETT policies.

Keywords: wheelset maintenance; wheel wear and rail damage; wear modelling; Archard wear model; rolling contact fatigue

\section{Background}

The GB Railway Industry is continuously seeking ways to improve cost effectiveness. There are opportunities to achieve this by implementing more efficient maintenance practices based on an improved understanding of component degradation rates and reviewing the suitability of existing intervention criteria.

A range of possible options have already been trialled in order to extend the life of railway wheelsets, including: trending of wheel lathe data to optimise turning intervals, application of improved wheel steels and novel lubrication systems. This paper considers another approach to reducing the amount of material removed during re-profiling, 'Economic Tyre Turning' (ETT). 
Depending on the vehicle type, new wheel diameters can vary, a typical new wheel diameter for a GB passenger train is $840 \mathrm{~mm}$. As a train operates the wheels gradually wear and are periodically re-profiled until they are scrapped when they reach a minimum diameter, for example $790 \mathrm{~mm} \mathrm{[2].} \mathrm{There} \mathrm{are} \mathrm{a}$ range of wheel profile designs specified in GB Railway Group Standard (RGS) GM/RT2466 [3] which includes limits on the geometry of those profiles as the wheels wear, such as flange height and thickness limits. Wheel profile geometry is monitored during a wheel's life, and wheels are re-profiled (typically once a year or at a pre-determined mileage) back to the 'as new' profile shape using wheel-lathes [4]; this process removes material from the diameter of the wheel in addition to the material removed through wear.

In order to turn a worn wheel profile with a flange thickness of $\approx 26 \mathrm{~mm}$ back to the original profile shape, with a flange thickness of $28.7 \mathrm{~mm}, 7 \mathrm{~mm}$ must be removed from the wheel radius (14 $\mathrm{mm}$ from the diameter) as illustrated in Figure 1. However, if the profile is restored using the design shape but a thinner flange of $26 \mathrm{~mm}$, this would only require removing $2 \mathrm{~mm}$ ( $4 \mathrm{~mm}$ from the diameter); this is known as Economic Tyre Turning.

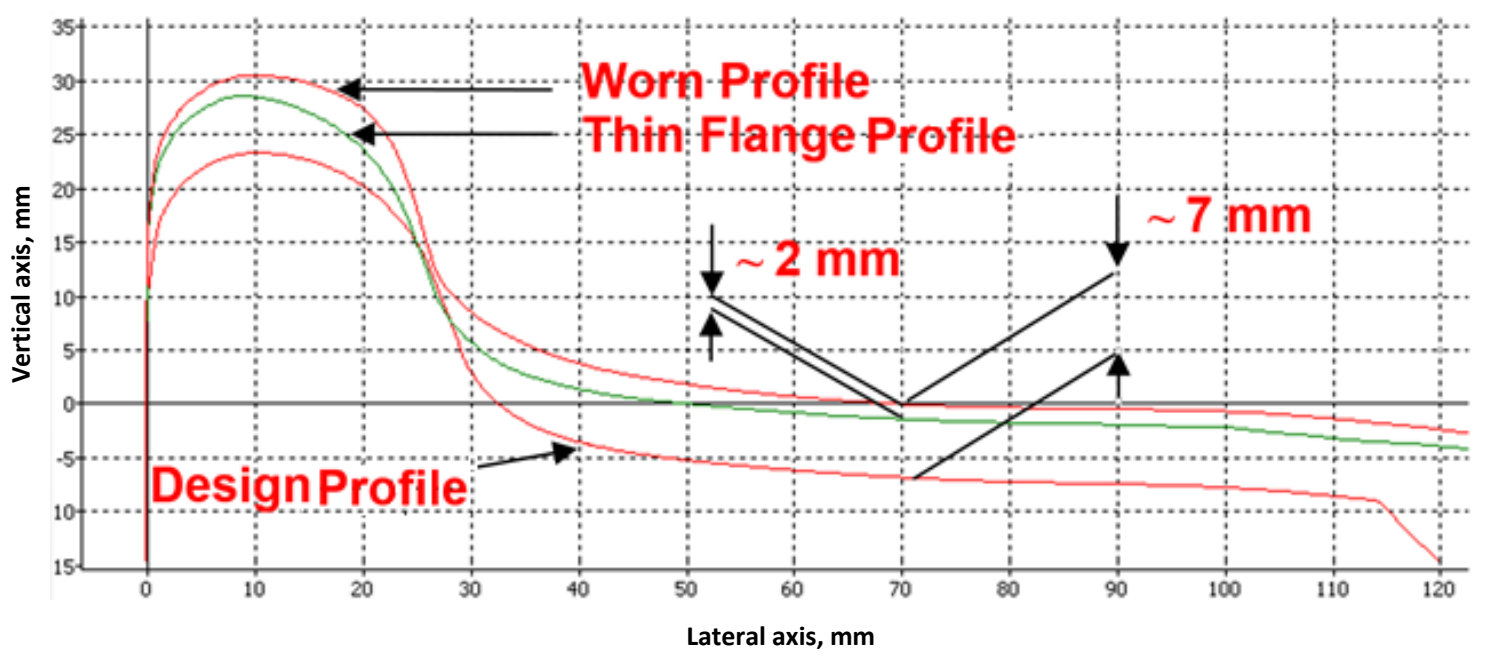

Figure 1: P12 Thin Flange Profiles Turned using Economic Tyre Turning

Although ETT is widely employed by other European Railway Administrations [2], ETT is not currently permitted by the GB Railway Group Standard (RGS) GM/RT2466 [3] which requires that the wheel profile is restored to a full design-case flange thickness when wheels are re-profiled.

Modern under-floor wheel lathes include functionality to allow the operator to choose a range of economic options for re-profiling wheelsets. These lathes typically provide the operator with a recommendation for the flange thickness which will remove the least material from the tread based on an algorithm within the lathe control software.

Previous work [2] has suggested that ETT could create potential savings of $2-5 \%$ of wheelset life cycle costs. These benefits are achieved by allowing one extra re-profiling at the end of the wheels life [5]. As a wheel is reaching its minimum diameter it is often not possible to re-profile with a full flange width and also keep the wheel above the minimum diameter, if a thinner flange is used, the wheel can be reprofiled without removing so much material.

Train maintainers typically replace wheelsets during a periodic heavy overhaul (as this is the opportunity to remove the wheelsets when the car bodies are lifted off the bogies). This can mean if a wheel 
diameter is close to half of the minimum (i.e. it is close to reaching half of its useful life) that wheelset has to be scrapped and a lot of the wheelset's theoretical life has been wasted. If ETT can be used to extend the wheel life enough so that the wheelset lasts for two heavy overhaul cycles, this can achieve significant savings in addition to the $2-5 \%$ previously estimated [2].

Wheels re-profiled with thinner flanges have a greater flangeway clearance and therefore a lower conicity (discussed further in section 3 ); this raises some potential concerns regarding ETT and suggests why it is not currently adopted in GB rail. These include:

- ETT profiles could generate more flange contact in curves, resulting in higher flange wear rates (in addition to the fact they are already thinner to begin with);

- The effect of ETT profiles on rail Rolling Contact Fatigue has not been quantified;

- The change in profile shape might introduce problems with vehicle stability.

The aim of this paper is to investigate the effect of adopting an ETT policy on wheel flange wear and rail RCF damage rates. This is demonstrated through the use of computer simulation and in-service trials.

\section{Wheels and Vehicles Selection}

This investigation considers P8 and P12 wheel profiles (both widely used wheel profiles for passenger vehicles in GB) running on Class 444 (suburban train fleet) [6] and Class 390 Pendolino (inter-city train fleet) [6], and a P6 wheel profile running on bulk cement freight wagon.

The P12 profile (The profile developed was named WRISA2)[7] is similar to the P8 profile but with two significant changes, an 'anti-RCF relief' in the flange root area and it has a lower initial conicity. The P6 profile is a 'worn' variant of the P1 profile commonly used on freight wagons and, unlike the P8 and P12 profiles, has a low equivalent conicity of approximately 0.05 .

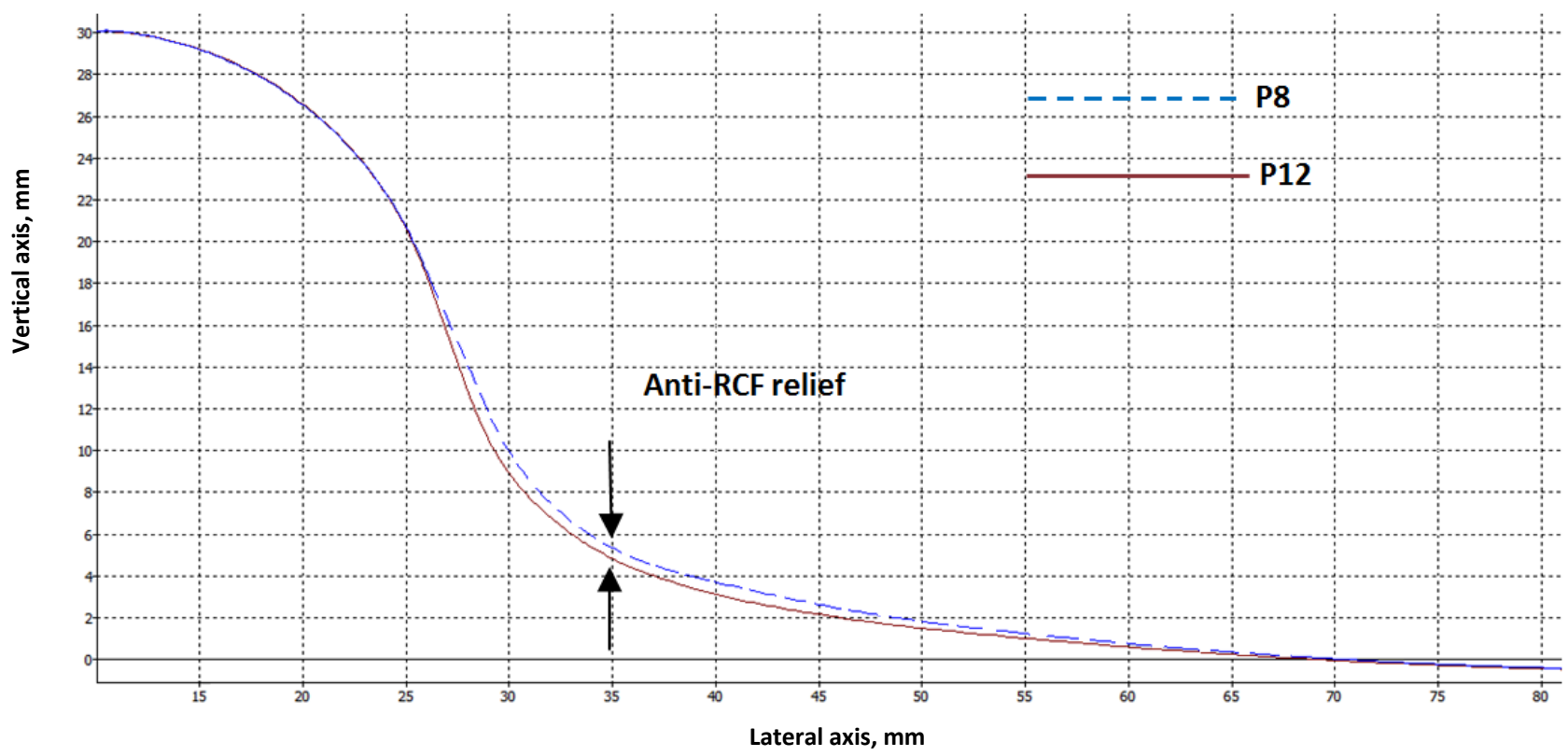

Figure 2: Flange root for P8 and P12 wheel profiles 
The selected wheel profiles (P8,P12 and P6) and vehicles were chosen for the study as they have a range of different characteristics, especially taking into account primary yaw stiffness and conicity, both of which have a significant effect on curving performance and therefore flange wear rates. The Class 444 has relatively soft primary yaw stiffness (PYS), whereas the Class 390, being designed for higher speeds has a higher PYS. The P6 profile has a low conicity compared to the other profiles and this was included to consider the effect of ETT on profiles that already have a low conicity in the design case, discussed further in section 3 . For the three cases, measured wheel profiles over time were available to calibrate the wear coefficients used in the model.

\section{Thin Flange Wheel Profile}

Existing wheel lathes do have an ETT option for re-profiling (not currently used in GB) that turns a new profile but with a thinner flange. For this study Network Rail, the GB infrastructure manager, used scrap wheels to turn P8 and P12 profiles with thin flanges, using a lathe ETT option. These measured profiles were provided for use in this study.

Figure 3 shows the P8 and P12 wheel profiles turned with thin flanges. P8 wheel profiles were turned with four different flange thicknesses at $1 \mathrm{~mm}$ intervals from $28 \mathrm{~mm}$ to $25 \mathrm{~mm}$. A P12 wheel profile was turned to $26 \mathrm{~mm}$ flange thickness (for both the P8 and P12 the normal design profiles have a flange thickness of $28.5 \mathrm{~mm}$ ).

Unlike the P8 and P12 profiles, measured P6 profiles that had been re-profiled with thin flanges were not available; it was therefore necessary to create some thin flange profiles, based on an approach created in previous work [5]. The whole P6 full thickness profile was shifted laterally from the tip of the flange to the tread run-out to provide the required flange thickness. The flange back and run-out were then modified to complete the profile. This approach follows the principles of BS EN 13715 [8] for

constructing the thinner flange wheel profiles. Three profiles were created with $27 \mathrm{~mm}, 26 \mathrm{~mm}$ and $25 \mathrm{~mm}$ flange thickness as shown in Figure 4. 


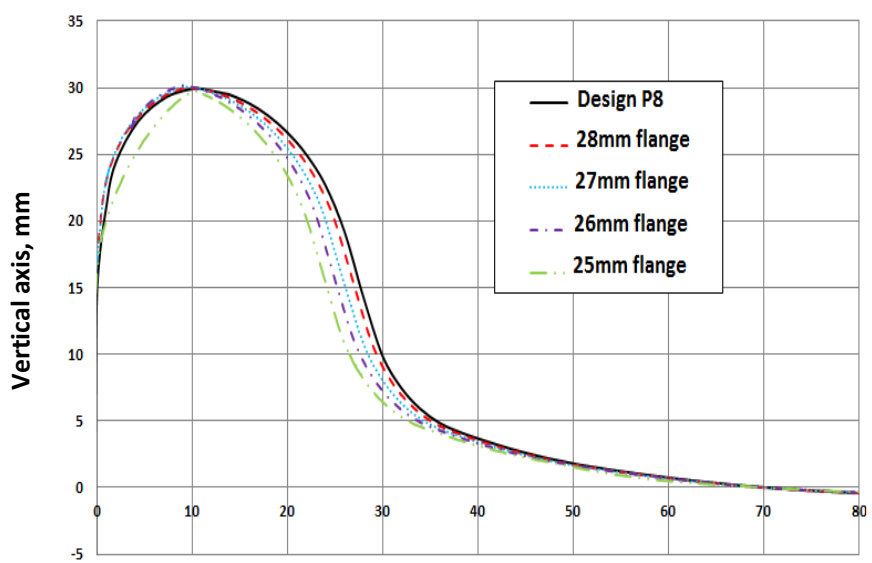

Lateral axis, $\mathrm{mm}$

(c) Thin Flange P8 Wheel Profiles

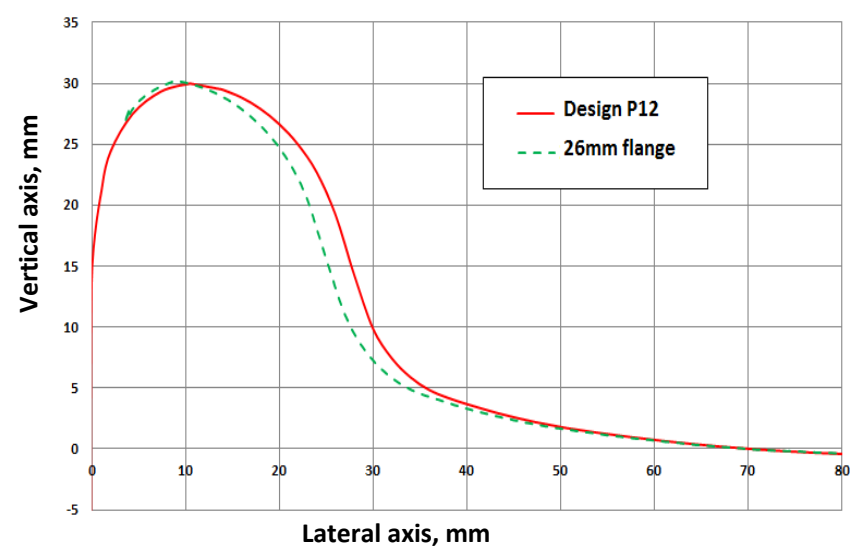

(c) Thin Flange P12 Wheel Profiles

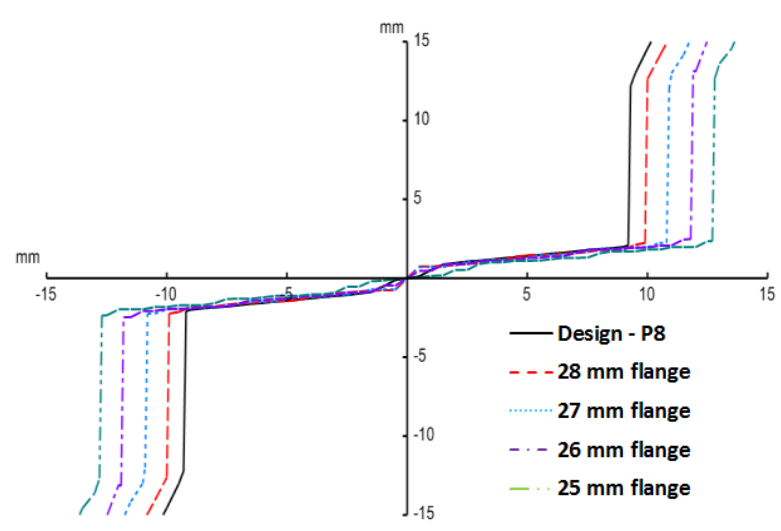

Lateral shifting, $\mathrm{mm}$

(b) Rolling Radius Difference - P8v Wheel Profiles

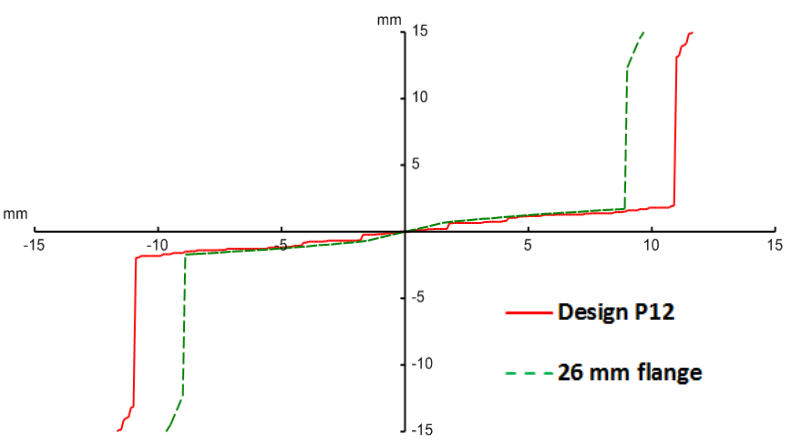

Lateral shifting, $\mathrm{mm}$

(d) Rolling Radius Difference - P12v Wheel Profiles

Figure 3: Turned Thin Flange P8 and P12 Wheel Profiles Compared with the Design Profile

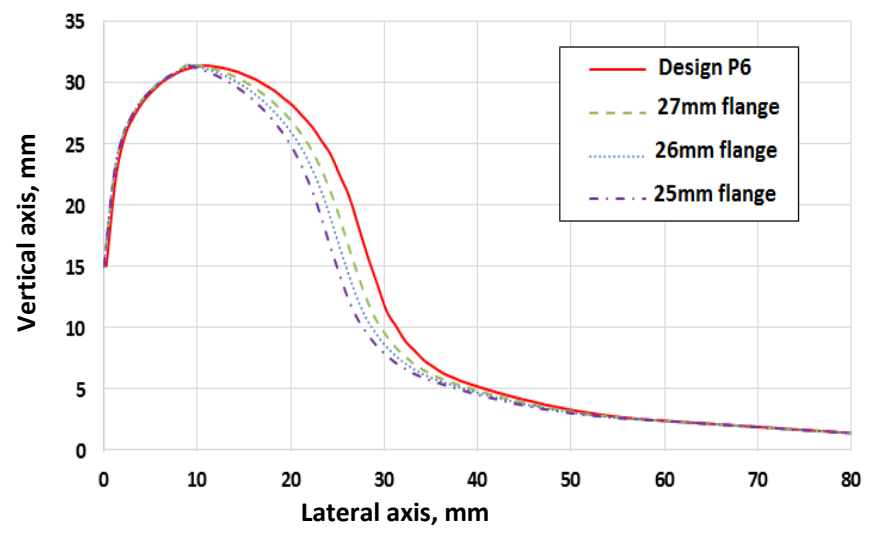

(a) Thin Flange P6 Wheel Profiles

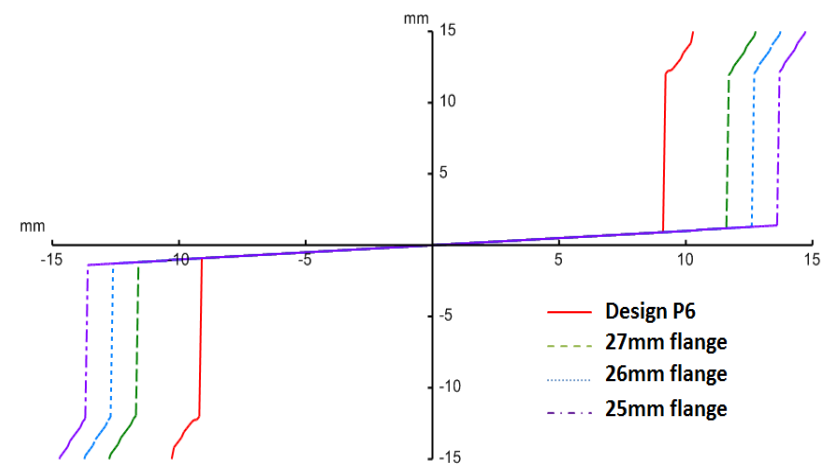

Lateral shifting, $\mathrm{mm}$

(b) Rolling Radius Difference - P6v Wheel Profiles

Figure 4: Design and Constructed Thin Flange Versions of P6 Wheel Profile 
For the three profiles considered, results show that the thin flange profiles give an almost identical rolling radius difference at flange contact as the design case. However, thinner flanges inevitably result in a larger flangeway clearance than the design profiles and as a result the thin flanges profiles have slightly lower equivalent conicities, as shown in Table 1.

\begin{tabular}{|c|c|c|c|c|c|}
\hline $\begin{array}{c}\text { Wheel } \\
\text { Profile }\end{array}$ & $\begin{array}{c}\text { Design } \\
\text { profile }\end{array}$ & ETT - 28mm & ETT - 27mm & ETT - 26mm & ETT - 25mm \\
\hline P8 & 0.18 & 0.17 & 0.16 & 0.16 & 0.12 \\
\hline P12 & 0.15 & - & - & 0.1 & - \\
\hline P6 & 0.05 & - & 0.05 & 0.05 & 0.05 \\
\hline
\end{tabular}

Table 1 : Equivalent Conicity - Design and Thin Flange Wheels on 56E1 Rail

\section{Wear Prediction}

There are two commonly used wear model types, used to predict wear in railway wheels and rails, frictional energy models and sliding modes according to the Archard method [9]. Frictional energy models relate the wear rate to the work done at the wheel /rail contact [10-12] whilst sliding models relate the wear rate to the sliding distance, normal force and hardness of the material $[10,13]$.

The Wheel Profile Damage Model (WPDM) [1] was used in this study, to predict wheel wear using the sliding model method. Previous studies $[1,10,13]$ have shown the sliding model gives wear predictions that correlate well with measured results.

The WPDM was developed to predict the wear pattern and rate for each wheelset type of a vehicle fleet. It uses a fleet's route diagram to characterise the duty cycle of the vehicle in terms of curve radius, cant deficiency and traction/braking performance[1].

In WPDM rail library representative rail profiles for use in the vehicle dynamics simulations are selected based on the curvature distribution of each route section. These have been selected to represent the average contact conditions that a wheel profile will observe during its life $[1,14]$.

Eight curvature bands are defined to determine the most appropriate rail profile pair to apply to each curve radius $(R)$ determined during the route characterisation process [1, 14].

The WDPM automatically runs the chosen analysis including:

- Running the route characterisation model: The route characterisation routine reads track geometry files (obtained by a track recording vehicle) together with vehicle speed along the route to represent different routes sections [1]. Later, the files are weighted in order to represent the frequency of operation of the vehicles running over the chosen routes. Based on that, the routine selects the appropriate curves radius and cant deficiency (typically 6-8 curve radii per route and 2-4 cant deficiencies per radii) bands based on their cumulative distributions[1]. More details for the routes characterisation methodology can be found in[1].

- Running VAMPIRE contact generation and transient analysis program: The vehicle dynamic simulation outputs include normal forces, size and location of the contact patch and creepages, 
which are used within the Archard wear model to predict the amount of material removal. This includes using the specific wheel profile and vehicle model.

- Running the wear prediction module: This routine used the wheel-rail contact data and forces generated from the vehicle dynamic simulations to calculate the wear of the wheel profile. After each iteration of the wear model, the wheel profile shape is updated. This process is repeated until the chosen mileages are reached.

\subsection{Wheel Wear Model}

The WPDM uses the Archard wear model [9] to determine the volume of material removed from the wheel profile. This method states that the volume of material loss $\left(V_{w}\right)$ is proportional to the normal force $(N)$ and sliding distance $(\mathrm{s})$ divided by the material hardness $(H)$ as shown below:

$V_{w}=K \frac{N \cdot s}{H}$

Equation 1

where $K$ represent the wear coefficient, which differs depending on the governing wear regime, see Figure 5.

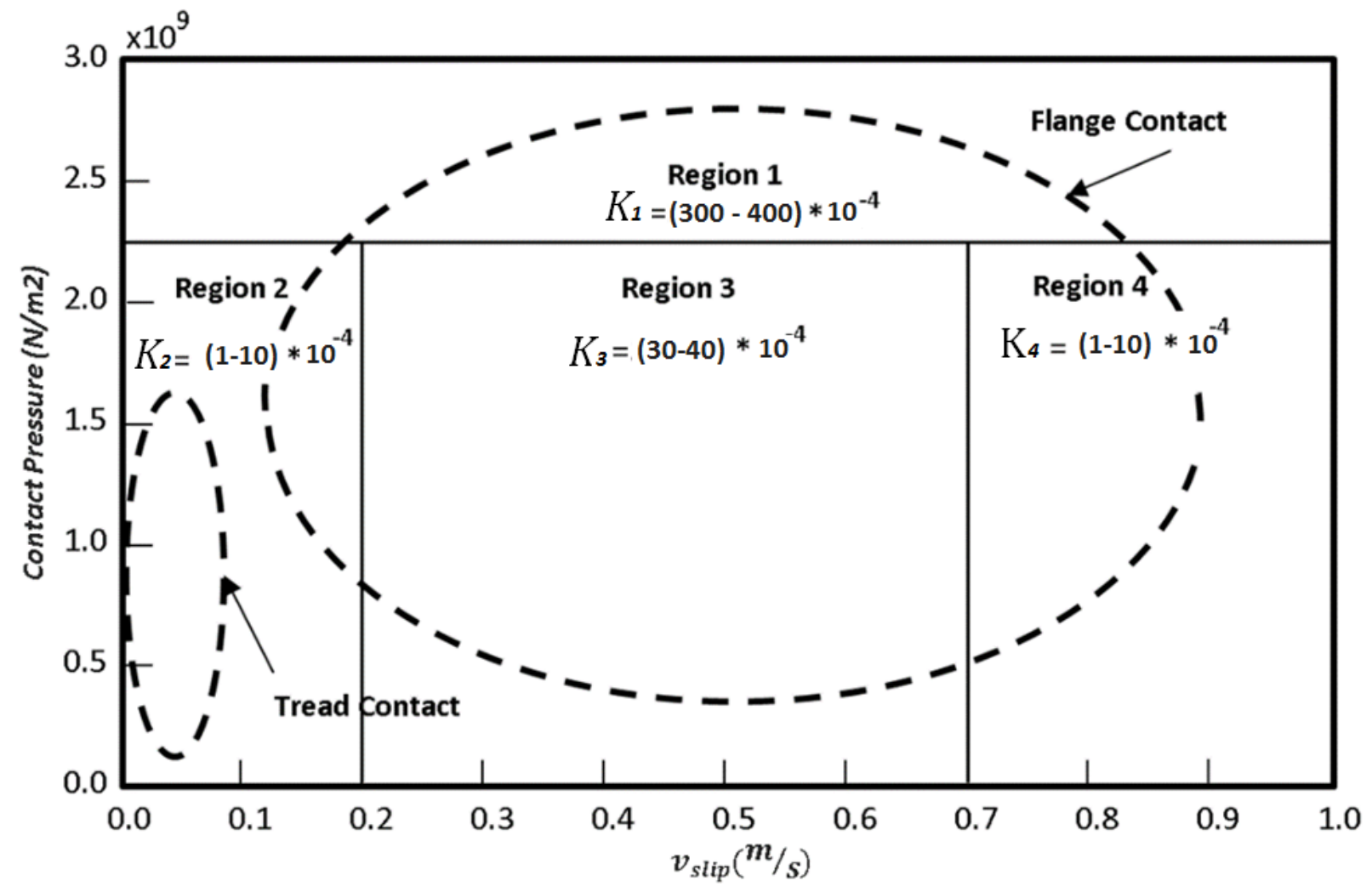

Figure 5: Archard Wear Map - Wear Coefficients for Tread and Flange Contact [9]

Figure 5 shows the value of the wear coefficients obtained by laboratory tests $[1,13,15]$ run on twin disc and pin-on-disc machines and field observation data. Where these coefficients are a function of slip velocity $\left(v_{s}\right)$ and contact pressure $(p)$.

An automated tool, launches the VAMPIRE vehicle dynamics simulation, and then uses the outputs to calculate the wear, as shown in Figure 6. 


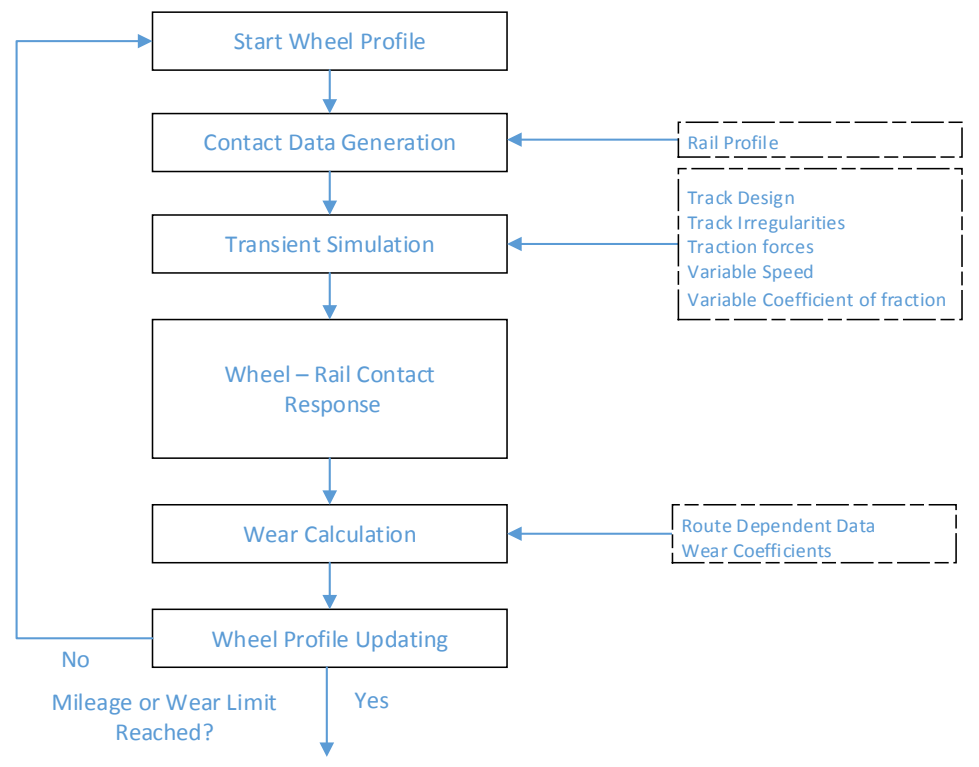

Figure 6: Wheel Wear Prediction Methodology

The WPDM uses the wear iteration procedure previously developed by Jendel [13] and successfully applied by Bevan, et al [1] to predict the wheel wear.

The output from the wheel wear prediction routines include the change in flange height $S_{h}$ (tread wear) and thickness $S_{d}$ (flange wear) with increasing running distance, see Figure 7 . These parameters are generally used to describe wheel profile wear and to determine wheel turning periodicity.

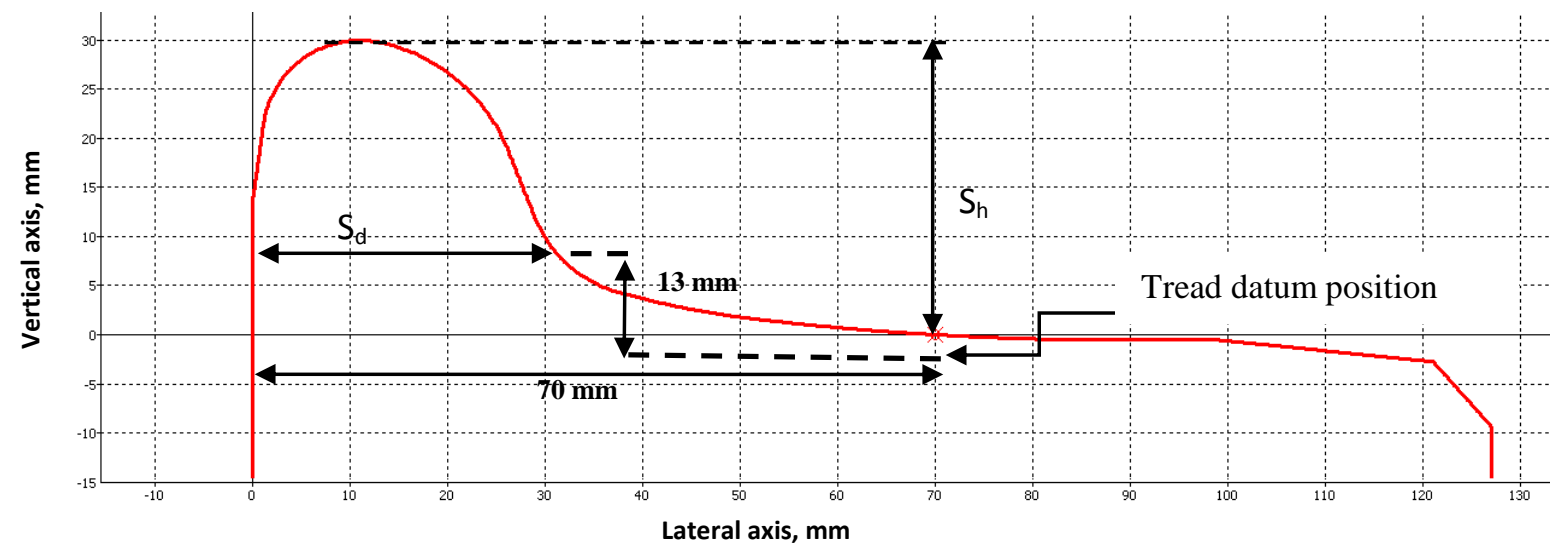

Figure 7: Definition of Flange Height $\left(S_{h}\right)$ and Flange Thickness $\left(S_{d}\right)$ 


\section{Calibration and Validation of the Wear Modelling}

The wear calculation includes factors to take into account the natural contact environment, the model wear coefficients. When the WPDM was developed, these factors were based on the average wear rates and wear shapes for a large number of fleets run on the GB network.

Whilst the WPDM produces wear predications that correlate well with the average results on a system level, the opportunity was taken to improve the accuracy of the predictions for the specific routes/fleets under consideration by calibrating the wear model against known wheel wear rates for the specific vehicles being used for the study. This was done by comparing the WPDM simulated worn wheels with measured worn wheel data from the vehicle fleets of interest.

The WPDM calibration process is essentially important to give a confidence to the ETT simulation results as will be shown later in Section 6 . The current study used $S_{h}$ and $S_{d}$ for evaluation and calibration purposes.

The calibration methodology was based on adjusting the wear coefficients and comparing the simulated results to measured worn wheel profiles of various mileages from the fleets of interest.

According to Archard wear model, the tread contact happens only on region 2 and the slip velocity was within the range of $0-0.9 \mathrm{~m} / \mathrm{s}$, referring to Figure 5 . However, the vehicle dynamic simulations for P8 wheel profiles on Class 444 showed that the tread contact happens on regions 2, 3 and 4 . Furthermore, the slip velocity reaches to $1.5 \mathrm{~m} / \mathrm{s}$, as shown in Figure 8 .

Each point in Figure 8 represents an element in the wheel-rail contact patch as calculated by FASTSIM algorithm[16]. The wear program takes the global outputs from Vampire and uses these within FASTSIM to discretise the contact patch and determine slip velocity and contact pressures for each element. 


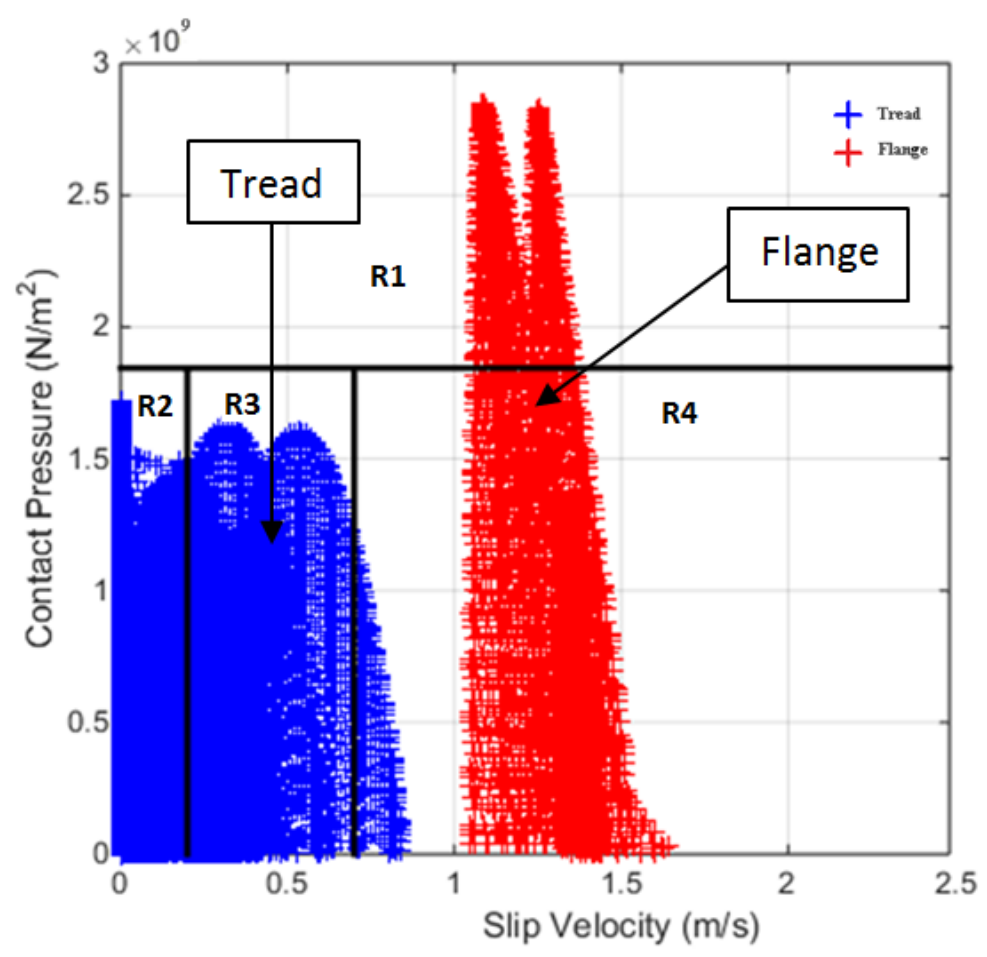

Figure 8: Wear chart showing tread and flange contacts

These differences are expected due to the fact that the wear chart in Figure 5 was obtained by laboratory tests using twin disc and pin-on-disc machines and field observation data. Given the complexity of the mechanisms involved and the wide variety of physical and environmental conditions encountered, it is not surprising therefore those tread/flange contact locations and hence wear coefficients will vary depending on the particular fleet and route.

Based on the above, the wear coefficients were modified based on the position of the tread and flange contacts on the wear chart.

Measured worn wheel P8 and P12 wheel profiles were obtained from Class 444s and Class 390s running various diagrams on Wessex and West Coast Main Line routes respectively. Similarly worn P6 wheel profiles were obtained from 2-axle freight carrying wagons running various diagrams on West Coast Main Line routes (slow lines).

\subsection{P8 Profiles on Class 444}

Figure 9 shows the simulated wear (in terms of flange height and thickness) for P8 wheel profile on class 444 trains before and after calibration. As there was considerable scatter in the measured data, the results were compared to the minimum, mean and maximum wheel profile measurements taken from vehicle operating on similar routes, for wheelset mileages of up to 100,000 miles post re-profiling.

Examination of the measured wheel profile data from class 444, shown in Figure 9 a), demonstrated that the average flange thickness reduces significantly in the first 20,000 mile, but thereafter tends to stabilise between 40,000 to 70,000 miles. 


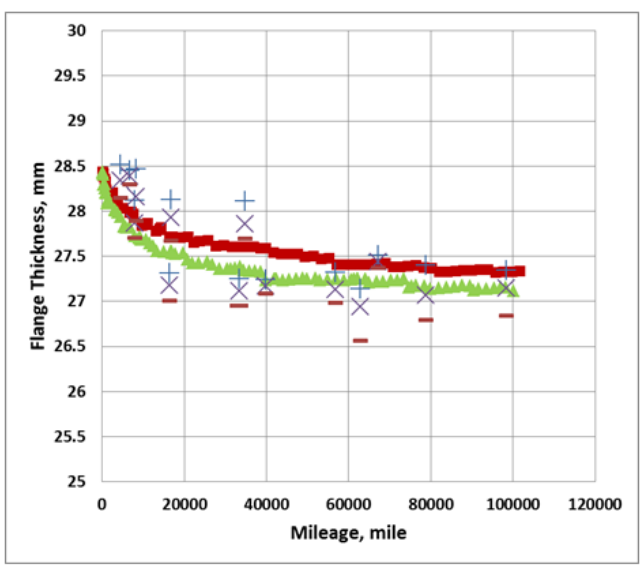

(a) Flange Thickness

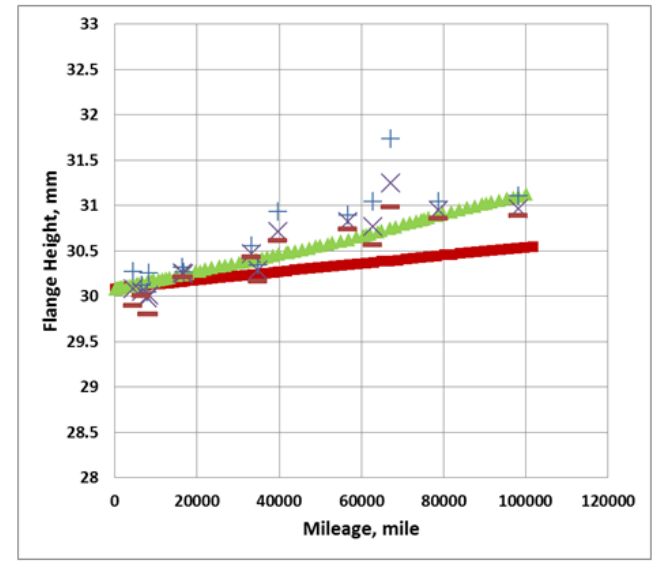

(b) Flange Height
- Before Calibration

$\triangle$ After Calibration

+ Max_Measured Profile

$\times$ Mean-Measured Profile

- Min-Measured Profile

Figure 9: Comparison between Measured and Simulated Flange Thickness and Flange HeightClass 444, P8 Profile

It can be seen in Figure 9 that the calibration procedure managed to adjust the simulation results to correlate well with the mean of the measured data.

\subsection{P8 on Class 390}

Using the same calibration methodology the WPDM was calibrated for class 390 s and the results for flange thickness and flange height after calibration are shown in Figure 10.

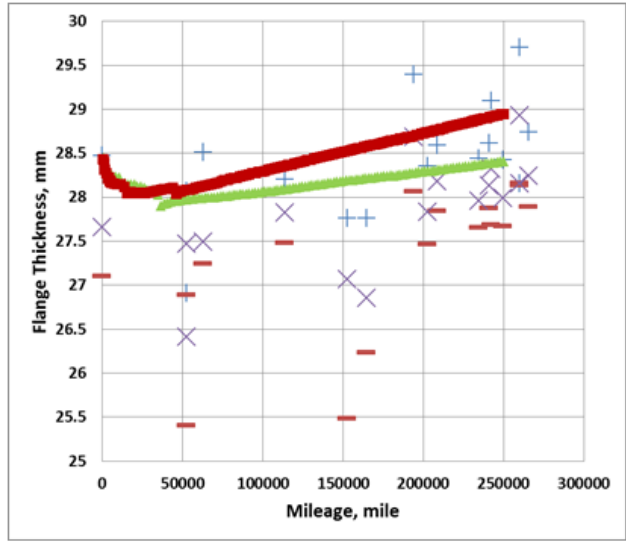

(a) Flange Thickness

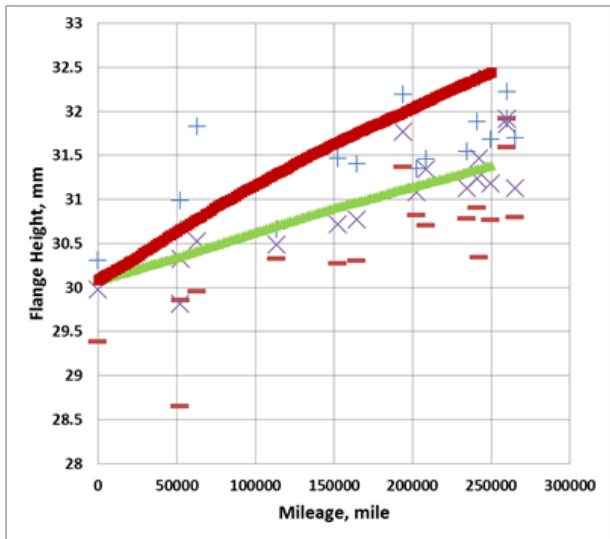

(b) Flange Height
- Before Calibration

$\triangle$ After Calibration

+ Max_Measured Profile Mean-Measured Profile

- Min-Measured Profile

Figure 10: Comparison between Measured and Simulated Flange Thickness and Flange Height - Class 390, P8 Profile

In the case of the class 390 trains, the measured data shows modest levels of tread and flange wear for P8 profiles. The data also shows a higher rate of flange wear in the first $40,000-50,000$ miles after turning which then stabilises between 50,000 to 100,000 miles. Beyond 150,000 miles flange thickness tends to increase, this is because as the tread wears, the position at which flange thickness is measured moves to remain $13 \mathrm{~mm}$ below the worn tread thus moving to a position on the flange that started off being wider. 
P8 results for class 444 and class 390 show a fairly linear relationship between the tread wear and running mileage. These trends are captured well in the simulated results. For class 390, the WPDM simulations were run to 250,000 miles to model the different wear rate behaviours (especially for the flange wear) as explained above.

The same simulation procedure was applied to P12 wheel profile and it was clear from the results that the simulated wear compares well to the measured values obtained in service for class 444 and class 390.

\subsection{P6 on a 2-axle freight wagon}

For the 2-axle freight wagon with disc brakes, measured worn wheel profiles were compared to simulated wear of a P6 wheel profile running up to 50,000 miles after re-profiling.

It is noteworthy that the mileage run between wheel turning for freight vehicles is much lower than passenger vehicles as it has a much higher flange wear rate and therefore infringes the min flange thickness limit at a much lower mileage.

The simulation was run under assumption that the wagon runs $50 \%$ of miles tare and $50 \%$ laden. Figure 11 shows flange thickness against flange height for simulated and measured data.

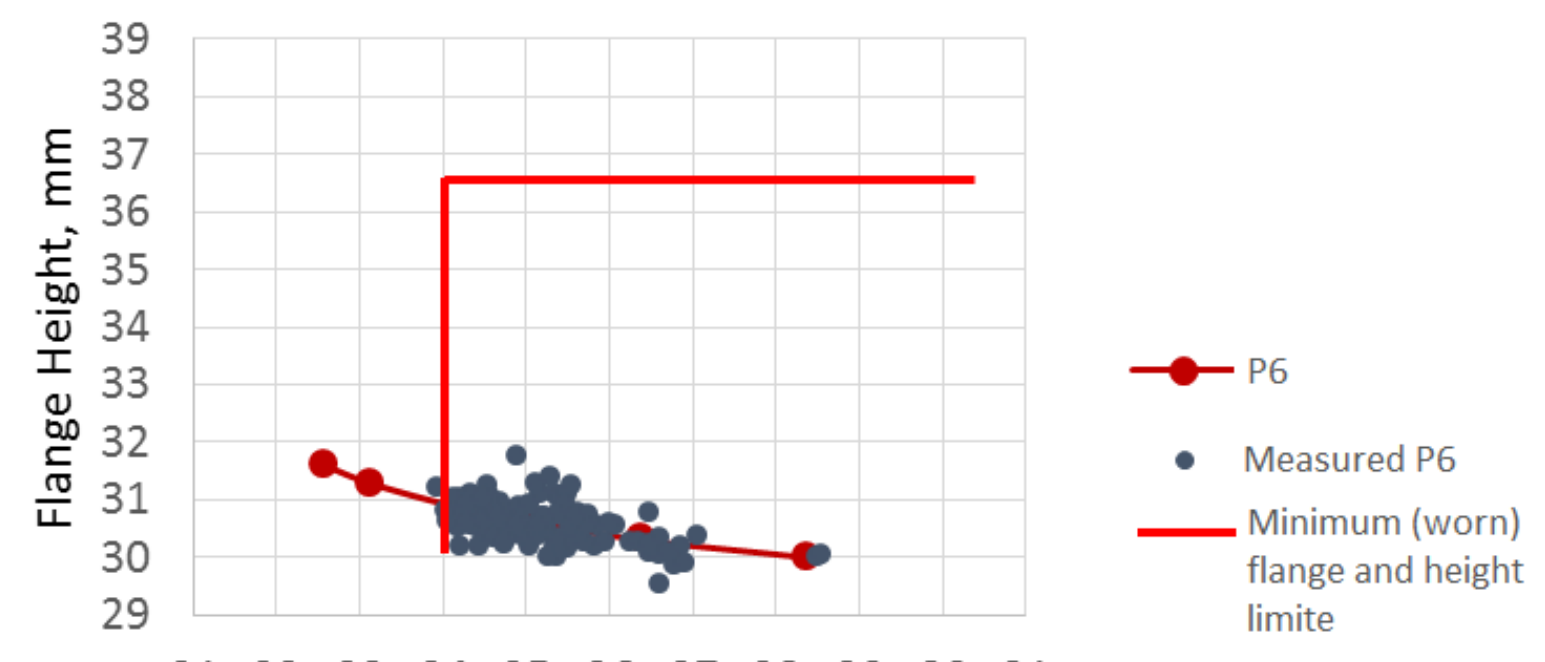

$\begin{array}{lllllllllll}21 & 22 & 23 & 24 & 25 & 26 & 27 & 28 & 29 & 30 & 31\end{array}$

Flange Thickness, $\mathrm{mm}$

Figure 11: Wheel Wear Trajectory for 2-axle Wagon, Simulated and Measured data

Examining the simulated and measured data indicates that the main wear mechanism is flange wear, i.e. the wear trajectory on this plot indicate that the flange thickness is wearing much faster than the wheel tread. For this poorly-steering vehicle with disc brakes we would expect flange wear to dominate, as seen here.

The results show that the P6 wheel profiles reached the minimum worn flange thickness (24mm for P6) at nearly 30,500 miles; whilst there was no excessive tread wear. The RSSB Wheel Tread Damage Guide 
[17] illustrates that the average turning interval for a P6 wheel profile running on a 2-axle freight wagon is 25000 miles, which correlated well with the predicted results.

The rate of flange wear is significantly higher than the two passenger vehicles included in this study. This is partially due to the vehicle being a 2 axle design, rather than a bogied design, and also due to the higher mass of the vehicle (when laden) and the lower conicity wheel profile. Additionally, it has a simple friction based suspension which permits limited wheelset steering.

\subsection{Summary of calibration against measured results}

The calibrated models have been demonstrated to show similar results compared to the average flange height and thickness evolution against wheelset mileage.

However, there is considerable scatter in the measured data for the cases examined; this could be due to the measured data containing collections of different vehicles (mix of trailer and motor) run through different routes with different infrastructure effects (such as curve lubricator effectiveness). Additionally, some vehicles may have had different duty and maintenance cycles.

Table 2 shows the differences between the wear coefficients finally selected for this investigation (for Class 444, Class 390 and 2-axle wagon) and those used by previous studies of X10 trains in Stockholm[13].

\begin{tabular}{|c|c|c|c|c|c|}
\hline Vehicle & Route & $K_{1}$ & $K_{2}$ & $K_{3}$ & $K_{4}$ \\
\hline X10 & $\begin{array}{c}\text { Commuter network- } \\
\text { Stockholm [10] }\end{array}$ & $350 * 10^{-4}$ & $4 * 10^{-4}$ & $35^{*} 10^{-4}$ & $5 * 10^{-4}$ \\
\hline Class 444 & Wessex - UK & $300 * 10^{-4}$ & $10^{*} 10^{-4}$ & $35^{*} 10^{-4}$ & $7 * 10^{-4}$ \\
\hline Class 390 & Coast Main Line - UK & $300 * 10^{-4}$ & $1 * 10^{-4}$ & $30^{*} 10^{-4}$ & $7 * 10^{-4}$ \\
\hline 2-axle Wagon & $\begin{array}{c}\text { Coast Main Line } \\
\text { (Slow Line) - UK }\end{array}$ & $300 * 10^{-4}$ & $1 * 10^{-4}$ & $30^{*} 10^{-4}$ & $7 * 10^{-4}$ \\
\hline
\end{tabular}

Table 2: Wear Coefficients

As shown in Table 2, the wear coefficients found to give the best match to measured worn profiles varied depending on the vehicle and route characteristics.

The largest variation between these wear coefficients was in region 2, referring to Figure 5 . This is mainly because for Class $444 \mathrm{~s}$ the simulated tread wear (before calibration) was lower than the averaged measured tread wear, hence the $K_{2}$ wear coefficient was increased to $10^{*} 10^{-4}$, whilst the simulated tread wear (before calibration) for Class 390 was higher than the averaged measured tread wear and therefore $K_{2}$ wear coefficient was reduced to $1^{*} 10^{-4}$.

For the current study, Class 390 wear coefficients tend to show a good match to measured worn profiles for the 2-axle freight wagon.

Overall, the calibration process showed that both predicted wear rates and patterns are highly sensitive to changes in wear coefficients. 
The calibrated models were used to investigate the effects of ETT, shown in Section 6.

\section{Wear Modelling Results - Thin Flange Profiles}

Figure 12 shows the predicted flange height and thickness from the WPDM for P8 and P12 wheel profiles on class 444 vehicles up to 100,000 miles post turning.

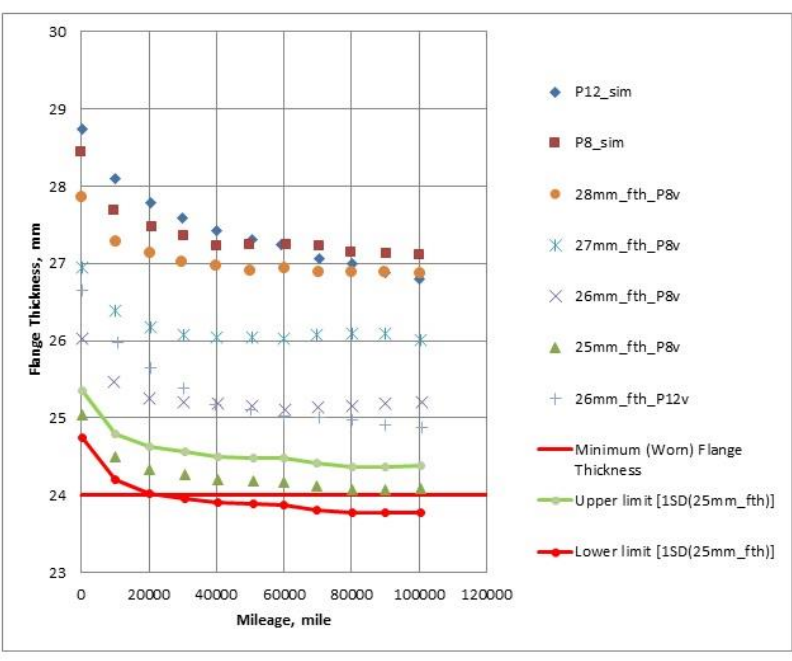

(a) Flange Thickness

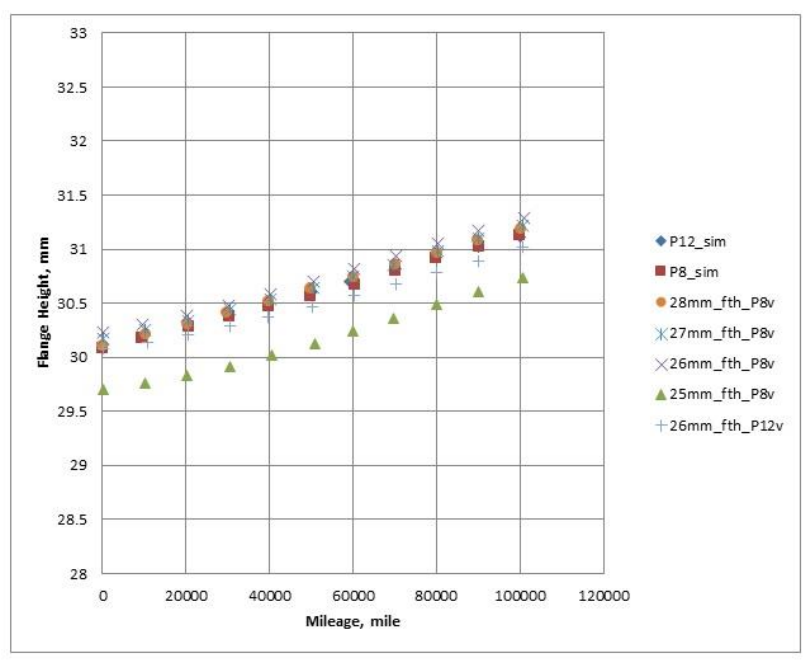

(b) Flange Height

Figure 12: Simulated Flange Thickness and Flange Height- Class 444

GB Railway Group Standard GM/RT2466 [3] defines the minimum worn flange thickness for P8 and P12 profiles as $24 \mathrm{~mm}$.

As shown in Figure 12 (b) the flange height increases linearly with the mileage run. For $28 \mathrm{~mm}$ to $26 \mathrm{~mm}$ thick P8 flanges the flange height starts nearly at the same height and then follows a similar pattern. However the $25 \mathrm{~mm}$ thick P8 flange starts off slightly short but grows in height at the same rate as the others. As shown in Figure 12 (a) the flange thickness reduces at a similar rate for all wheel profiles considered, flange thickness reduces significantly in the first 20,000 miles and then stabilises between 40,000 and 60,000 miles. The upper and lower worn limits shown for the P8 which starts with a $25 \mathrm{~mm}$ flange thickness in Figure 12 (a) represent the possible (i.e. estimated) effect of the scatter observed in the measured data on the simulation flange thickness results. These limits were defined as: simulated flange thickness \pm 1 standard deviation $\sigma$ of the absolute error $\varepsilon_{i}^{a b s}$ (the absolute error between the measured data and simulated results of design P8). These limits are the representative amount of variation in flange wear being experienced by such services.

The simulation results show that the flange wear for the $25 \mathrm{~mm}$ flange remain within the RGS limits up to 100,000 miles. However, it can be seen that when the effect of the considerable scatter in the measured data is added, the minimum flange thickness may be reached for some wheels at only 20,000 miles after turning. 
Figure 13 shows the simulated flange height and thickness for class 390 run up to 100,000 miles. The results show clearly that there is no excessive tread / flange wear in any of the cases considered and the flange wear for the considered cases remains less $24 \mathrm{~mm}$.

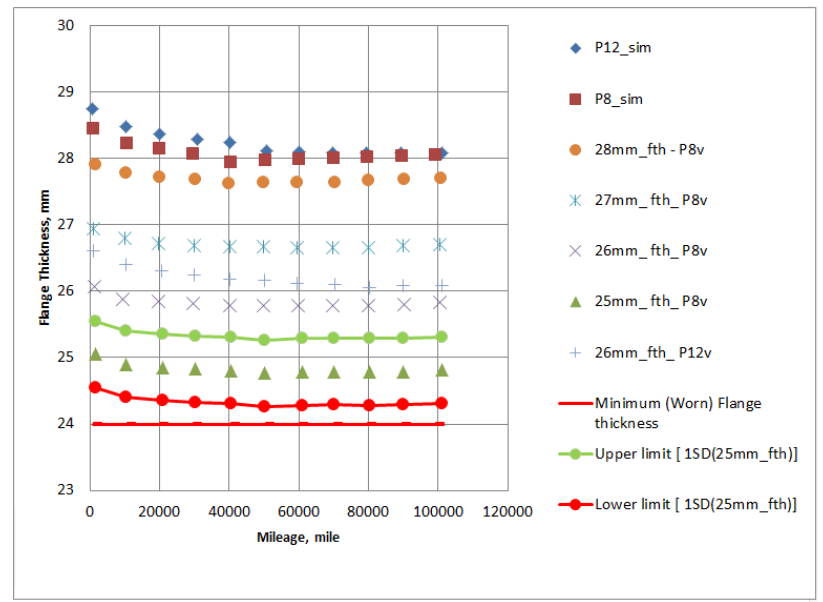

(a) Flange Thickness

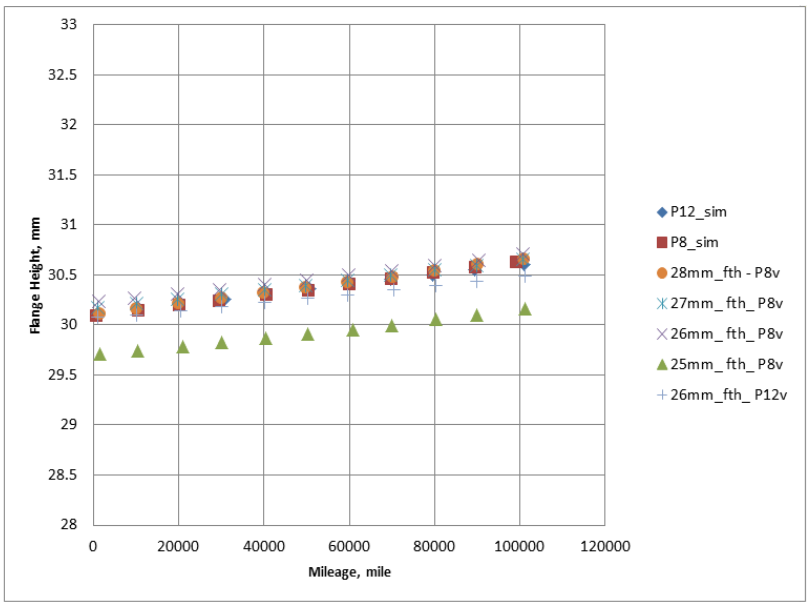

(b) Flange Height

Figure 13: Simulated Flange Thickness and Flange Height- Class 390

Following the same procedure shown previously, the wear rate/patterns were predicted for P6 thin flange profiles with flange thicknesses between $25 \mathrm{~mm}$ and $27 \mathrm{~mm}$ (in $1 \mathrm{~mm}$ increments).

Figure 14 shows the simulated results of the flange thickness and the flange height. The wear modelling was run under assumption that the vehicle has two loading conditions; laden and tare.

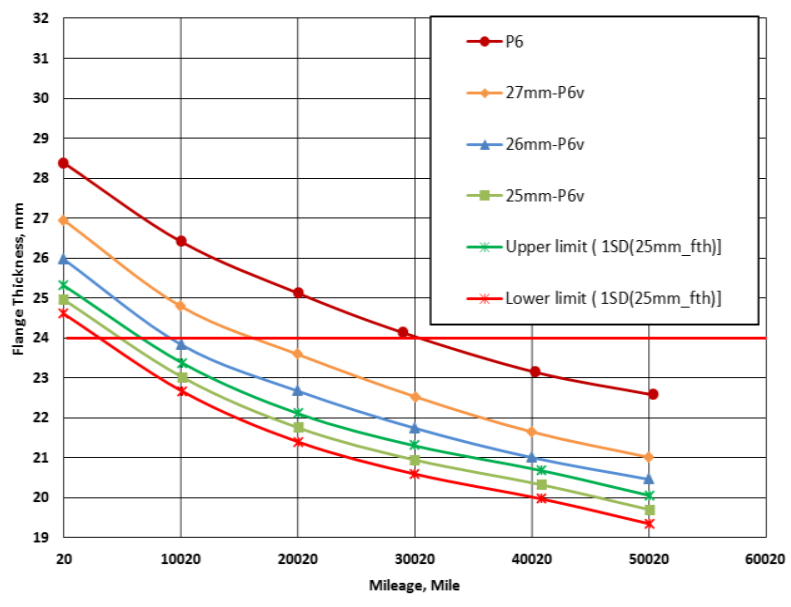

(a) Flange Thickness

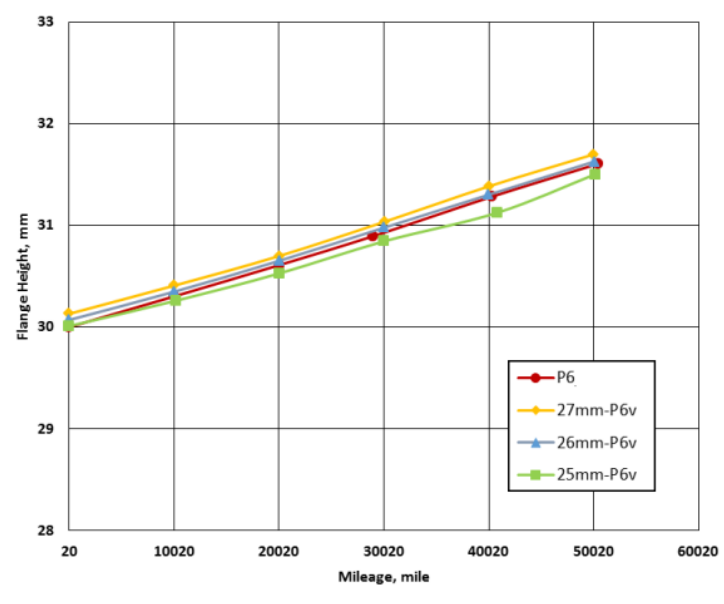

(b) Flange Height

Figure 14: Simulated Flange Thickness and Flange Height, 2-axle Wagon 
As shown in Figure 14 (a) the $27 \mathrm{~mm}$ flange thickness reaches the minimum flange worn limit at 16000 mile and this distance reduce proportionally with flange thickness to reach 9300 mile for $26 \mathrm{~mm}$ flange thickness and 4200 for $25 \mathrm{~mm}$ flange thickness. This indicate that the thinner flange profiles will have lower average turning interval mileage compared to the design P6 case, see Table 3.

\begin{tabular}{|c|c|c|c|}
\hline Wheel profile & $\begin{array}{c}\text { Tread wear rate } \\
\emptyset \mathbf{~ m m} \text { / 1000 mile }\end{array}$ & $\begin{array}{c}\text { Flange wear rate } \\
\emptyset \mathbf{~ m m ~ / ~ 1 0 0 0 ~ m i l e ~}\end{array}$ & $\begin{array}{c}\text { Average turning } \\
\text { interval }\end{array}$ \\
\hline Design P6-measured Data & 0.04 & 0.13 & 25000 \\
\hline Design P6-simulated Data & 0.03 & 0.12 & 30000 \\
\hline $27 \mathrm{~mm}-\mathrm{P6}$ & 0.03 & 0.12 & 16000 \\
\hline $26 \mathrm{~mm}-\mathrm{P6}$ & 0.03 & 0.11 & 9300 \\
\hline $25 \mathrm{~mm}-\mathrm{P6}$ & 0.03 & 0.1 & 4200 \\
\hline
\end{tabular}

Table 3: Wear Rate per 1000 Mile, 2-axle Wagon

Overall, the simulated results show that the thin flange profiles have roughly the same tread and flange wear rates for the first 100,000 miles run after wheel turning.

\section{Rolling Contact Fatigue Damage Prediction}

There are two main methods for predicting Rolling Contact Fatigue (RCF)[17-19] in wheels and rails. These methods are Shakedown theory and frictional energy based model.

The Shakedown theory $[10,20,21]$ correlates the critical shear stress of material $(k)$, normal contact stress $(p o)$, and traction coefficient $(\mu)$ at the contact patch, as shown in Figure 15. 


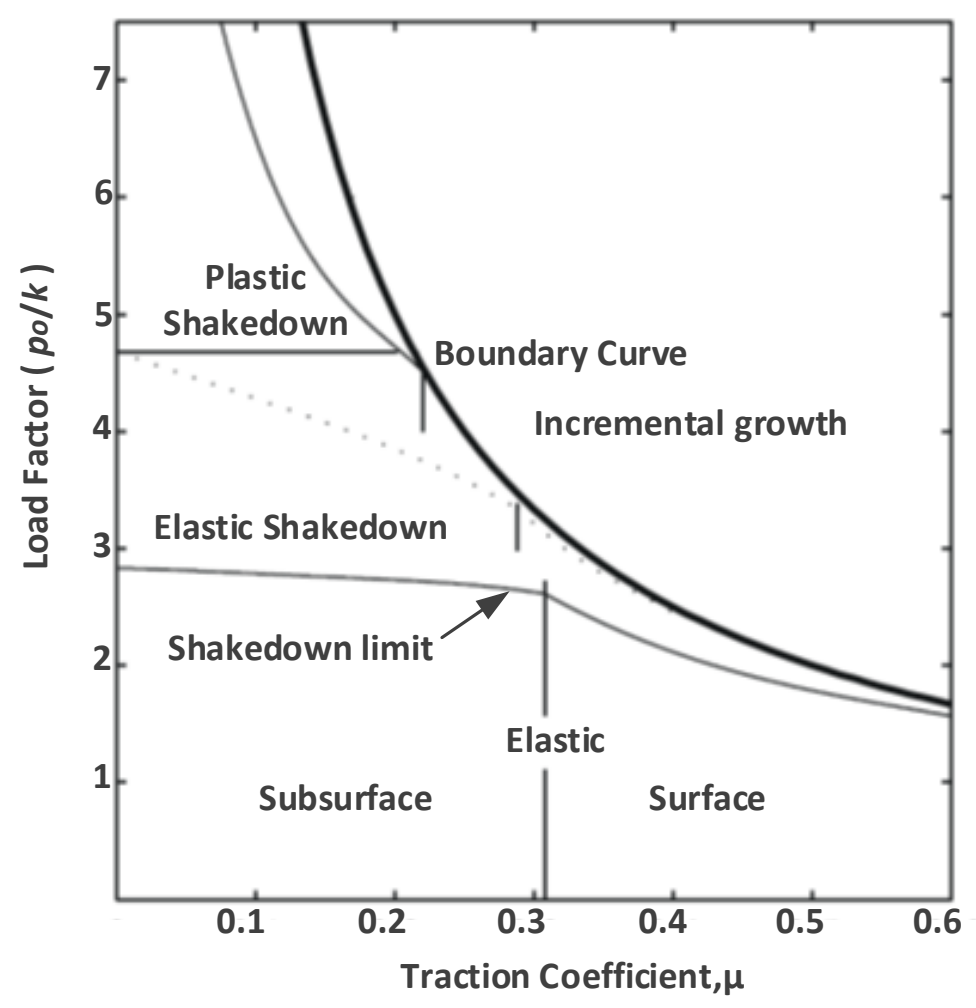

Figure 15: Shakedown Diagram [10]

This method states that RCF can be expected if the contact lies above the shakedown limit. Shakedown theory has been applied to study the establishment and development of RCF; however, this method does not account the competing effect of the wear, where increasing the level of wear will remove the RCF damage from the rail.

A frictional energy ( $T \gamma$ ) based model proposed by Burstow [19] was adopted in the current investigation to predict the RCF damage on rails. According to this model, the fatigue damage depends on the values of the frictional energy $T \gamma$ in the wheel-rail contact patch (where $T=$ creep force and $\gamma=$ creepage). Figure 15 shows the relationship between RCF damage index and the TY. 


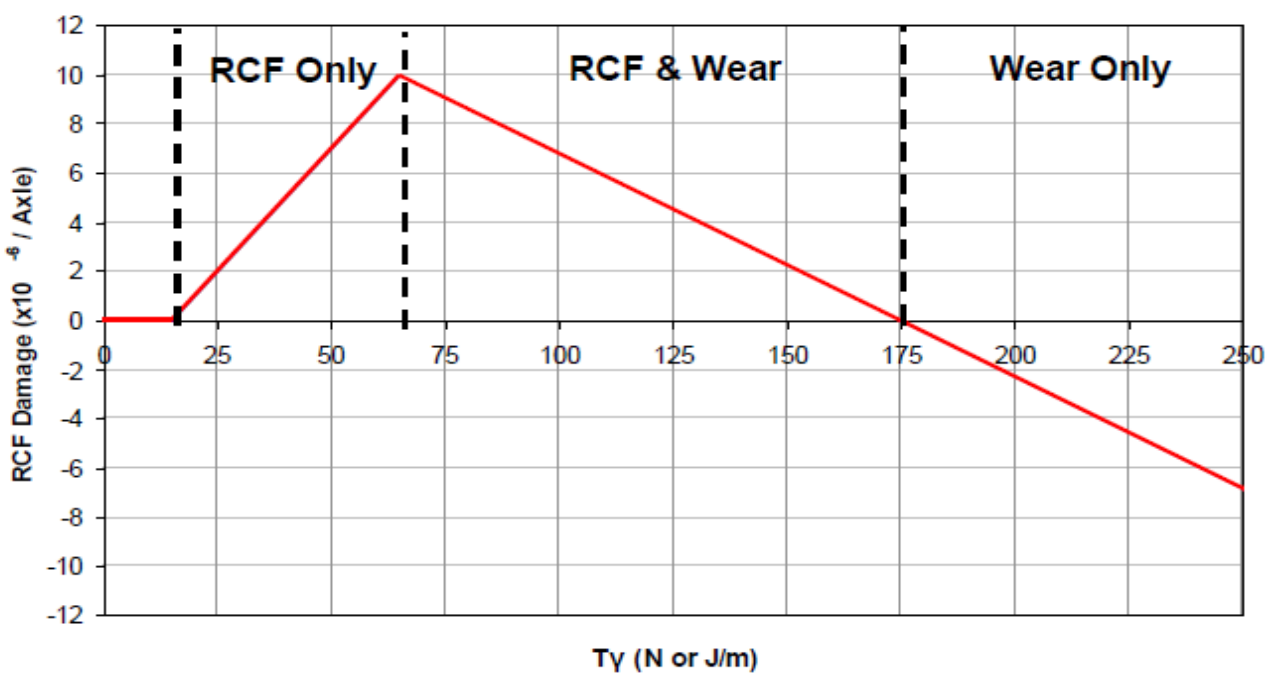

Figure 16: Whole Life Rail Model (WLRM) Damage Function [19]

As shown in Figure 16, when $T_{\gamma}$ values lie between $15 \mathrm{~N}$ and $65 \mathrm{~N}$, RCF cracks initiate and grow faster than they are removed by the small mounts of wear present. As Ty increases above the peak at $65 \mathrm{~N} \mathrm{RCF}$ occurs in combination with wear becoming increasingly dominant. At $T_{\gamma}$ values over $175 \mathrm{~N}$ the wear rate is high enough to remove the initiating RCF cracks before they can propagate into the rail material.

VAMPIRE dynamic simulations were used to identify the effect of flange thickness on vehicle curving at radii between 200 to $2000 \mathrm{~m}$ (at $40 \mathrm{~mm}, 75 \mathrm{~mm}$ and $110 \mathrm{~mm}$ cant deficiencies). Ty was calculated for each radii and the Whole Life Rail Model (WLRM) [9] damage function used to predict the RCF damage. Two design case rail profiles (56E1 and CEN 60E2) [22] together with a selection of worn wheel and rail profiles were used in these simulations. These profiles are commonly used within the UK network. The worn rails profiles have been taken from the Wheel Profile Damage Model (WPDM) rail profile library for curves with a radius of $500 \mathrm{~m}$ and $1300 \mathrm{~m}$ [14].

The magnitudes and the range of radii where RCF damage occurs for Class 444 differs from Class 390 due to the differences in primary suspension yaw stiffness. As shown in Figure 17, the RCF results show that thin flange versions of P8 and P12 profiles tend to generate similar RCF damage to full flange P8 and P12 profiles in the cases studied, especially between 600 and $1400 \mathrm{~m}$ radius, however there are detail differences depending on flange thickness and curving conditions. Overall, the results indicated that only $25 \mathrm{~mm}$ flange thickness profiles are likely to generate some additional damage most notably for radii between 800-1400 m. However wheels starting off with these thinner flanges will be in service for the shortest amount of time. 

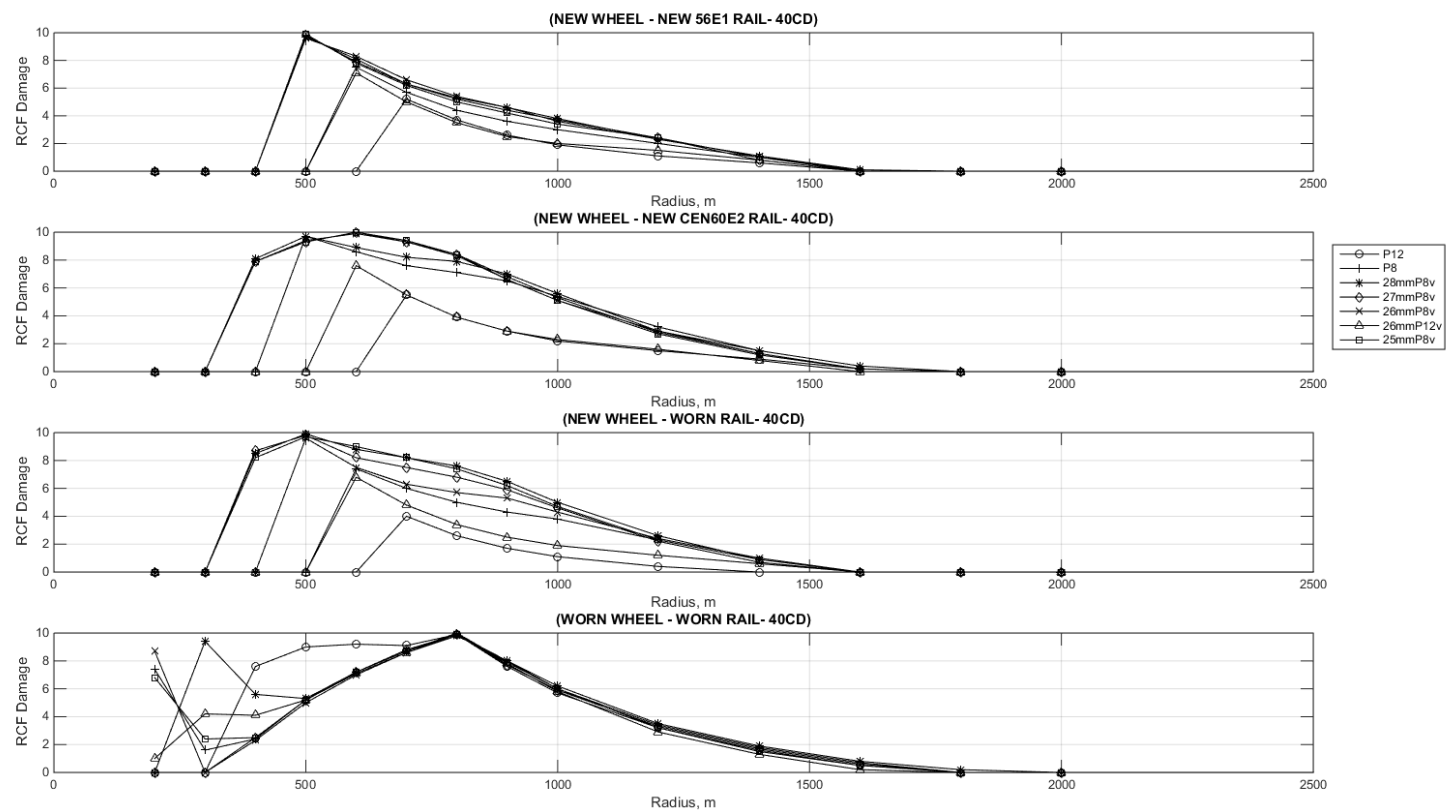

Figure 17: RCF Damage on High Rail - Class 444, cant deficiency 40mm

\section{Class 390 Economic Tyre Turning Trial}

Results of the wheel wear simulations, presented in section 6 , showed that thin flange profiles will have the same wear rate as the design case (full flange) wheel profile. This provides strong evidence that one of the concerns about ETT as presented in section 1, i.e. that wear rates might be higher for thin flange profiles, is not valid. To confirm this is the case, an in-service trial using thin flange wheels, re-profiled in line with ETT practices was carried out.

The trial commenced on $17^{\text {th }}$ December 2015, when Alstom Transport turned 20 axles on 5 vehicles to $26 \mathrm{~mm}$ flange thickness P12 wheel profiles. The remaining wheels on the train were turned to a full flange P12 profiles for comparison purposes. The trial ran until $18^{\text {th }}$ March 2016 when the train was withdrawn from service for a planned overhaul having covered around 70,000 miles during the trial period.

The trial showed that using Economic Tyre Turning allowed less material to be removed from the wheel diameter at re-profiling. The averaged material removed from the wheel diameter using Economic Tyre Turning was $2.0 \mathrm{~mm}$, whilst the averaged material removed from the wheel diameter using Standard Tyre Turning was $7.7 \mathrm{~mm}$.

Figure 18 shows the measured wear for full and thin flange thickness P12 wheel profile on the class 390 vehicle. 


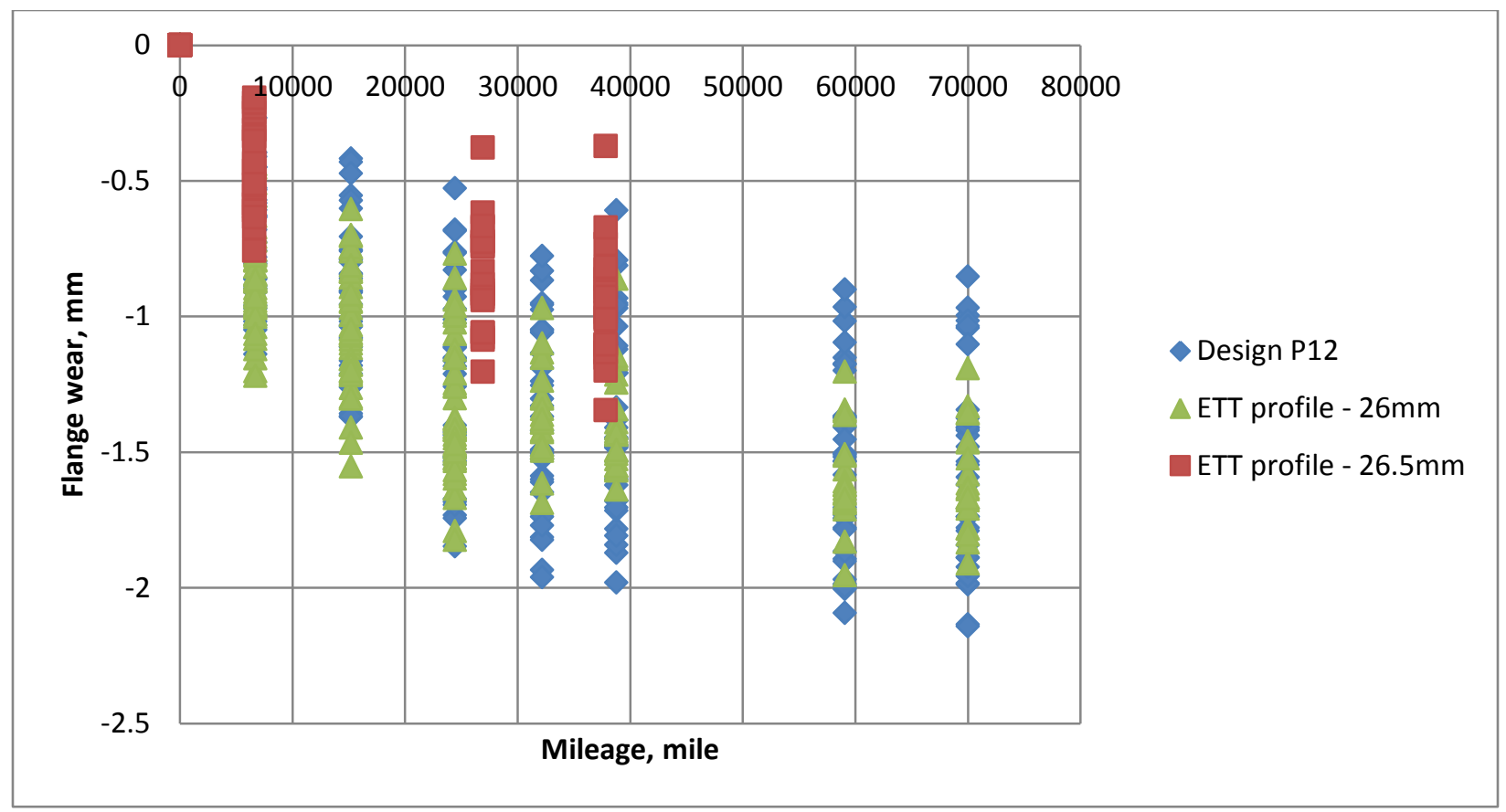

Figure 18: Measured Flange Thickness - Full and Thin Flange Thickness, P12 Profiles

The measured change in flange thickness over time shows a similar pattern to the simulated results for both the design case P12 profile and the thin flange P12 profile. As with the simulated results there was significant reduction in the flange thickness in the first 20,000 miles after re-profiling and this tended to stabilise between 40,000 to 70,000 miles. The measured data for the design P12 shows that the flange wear was between 0.8 to $2.1 \mathrm{~mm}$ over 70,000 miles in service.

There is no obvious reason behind this variation in the flange wear. It could be due to differences in the vehicle type (motor or trailer), bogie setup issue or a function of the way the wheels are turned.

For the thin flange P12 profile, the average flange thickness did not reach the allowable limit of $24 \mathrm{~mm}$. However, the wheels with the highest initial flange rate did get close to the minimum flange thickness $(24 \mathrm{~mm})$ after 25,000 miles. These were on a driving motor vehicle and two adjacent vehicles. Because of this these wheelset, plus 14 wheels more (for the purpose of wheel diameter parity) were re-turned to $26.5 \mathrm{~mm}$ flange thickness as shown in Figure 18. The remaining 10 axles accumulated over 70,000 miles in-service with a minimum flange thickness equal to $24.2 \mathrm{~mm}$. Figure 18 also shows how the flange thickness evolved post turning on the 20 wheelsets that were re-profiled to $26.5 \mathrm{~mm}$ flange thickness.

The initial flange wear rate from the set of profiles which were re-profiled to a $26.5 \mathrm{~mm}$ thick flange appears to be slightly lower than the full flange and $26 \mathrm{~mm}$ thick flange; this is not considered to be because of the extra additional $0.5 \mathrm{~mm}$ flange thickness but is attributed to changes in the vehicle's operating route towards the end of the trial.

The flange wear results for both thin and full flange P12 profiles show a considerable scatter in the measured data, which is similar for both the full flange and thin flange profiles; this is in line with the predicted scatter shown earlier in Figure 9 and Figure 10.

As shown in Figure 19, the conicity calculation shows that the profiles with thin flanges thickness have lower conicity values compared to full flange thickness wheels. The results show that the equivalent 
conicity reduces in the first 20,000 to 40,000 miles and thereafter stabilised between 60,000 and 70,000 miles.

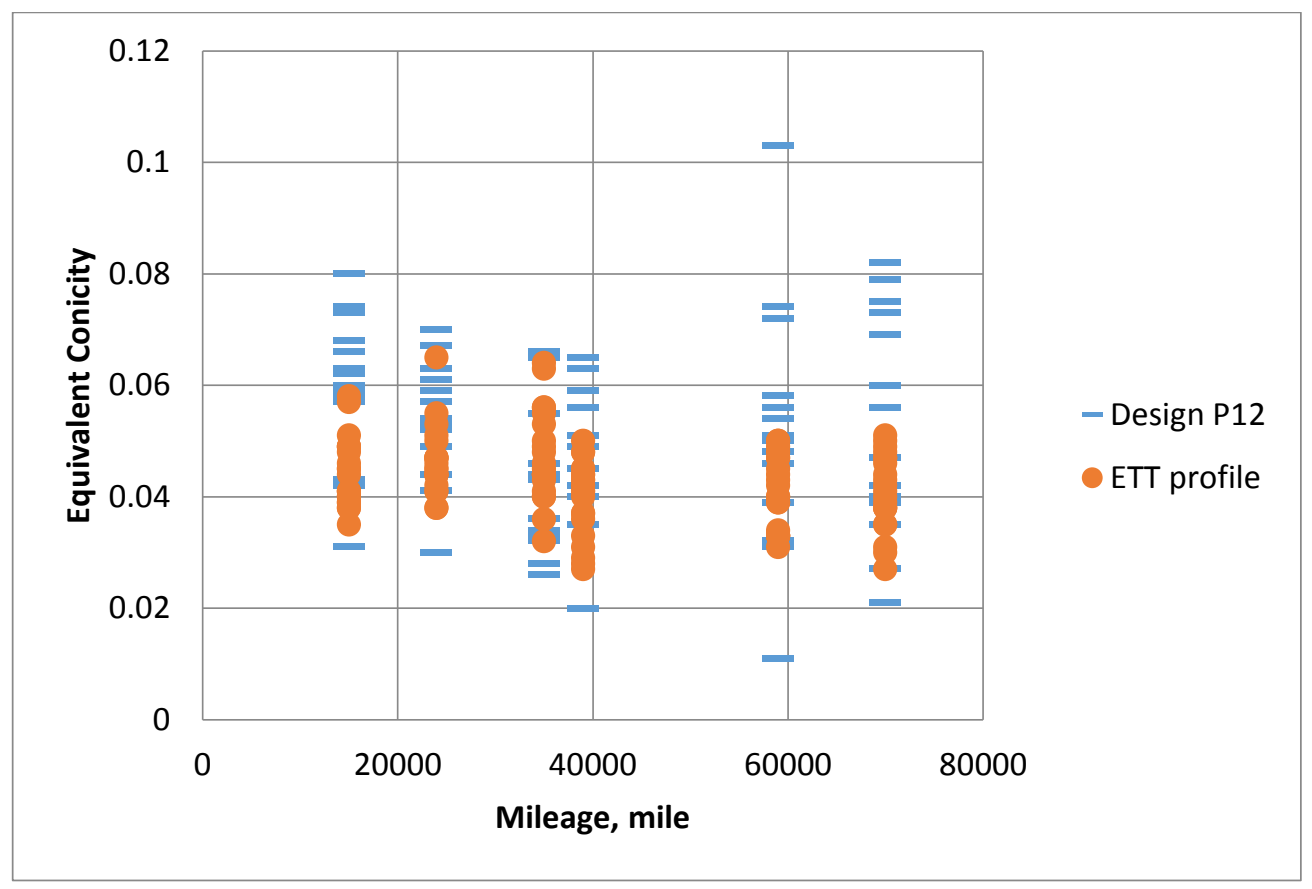

Figure 19: Equivalent Conicity - rail profile CEN 60E2 and track gauge 1438mm

The conicity values, for $1438 \mathrm{~mm}$ track gauge and CEN 60E2rail profile, were between 0.03 and 0.085 for full flange thickness profiles and between 0.03 and 0.06 for the thin flange thickness profiles. Although these figures are low, the trial results show that low conicity values did not increase the flange wear. As noted in Section 3, whilst the conicity may be reduced due to the use of a thinner flange, the actual rolling radius difference which is generated approaching flange contact is typically the same, or very similar, to a full flange profile.

As a result of the trial, the measured wheel profile development confirmed the predicted pattern in flange wear, with a higher initial wear rate that stabilised after 40,000 miles. The trial also showed that there were similar average wear rates and a similar scatter in the wear rates for both the full flange and thin flange profiles.

\section{Conclusions}

The Wheel Profile Damage Model (WPDM) has been developed to predict the rate of wear on the wheel. The model wear coefficients in WPDM were fixed based on the average wear rates and wear shapes for a large number of fleets run on the GB network, therefore the wear coefficients were modified depending on the particular fleet and route. This was done by calibrating the wear model against measured worn wheel data from the vehicle fleets of interest.

The results show that the WPDM gives good predictions of the wear rate and pattern of the P8 and P12 profiles running to high mileages on both Class 444s and Class 390s and P6 profiles running on 2-axle freight wagon. 
The calibration and validation processes for the WPDM indicated that the tread/flange contact locations on the wear chart and hence wear coefficients will vary depending on the particular fleet and route.

The validation exercise provides a high degree of confidence in the obtained results of the simulations of thin flange versions of these profiles.

The simulation results suggested that the wear rate and wear pattern of the ETT thin flange profiles is similar to design case (full flange) profiles; the thin flange profiles did not result in a higher wear rate. For the passenger train cases, the results show that the thin flange profiles have almost the same wear pattern as design P8 and P12 profiles. For the 2-axle wagon, the results indicated that thin flange P6 profiles have the same flange/tread wear rates as the design case, yet these profiles will have lower average turning interval mileage compared to the design case.

Except for the $25 \mathrm{~mm}$ thick flange wheel profile, where a very modest increase in rail RCF damage was noted, the results of the RCF investigation showed that wheels re-profiles with thin flanges did not tend to cause more rail RCF.

Overall, the simulation and trial outcomes provide valuable and strong evidence to support the case that train maintainers should be allowed to implement ETT policies. This will provide the opportunity to exploit the cost savings associated with ETT without a significant detrimental effect on the infrastructure over which they operate.

\section{Acknowledgements}

This project has been undertaken as part of the Strategic Partnership between RSSB and the University of Huddersfield. The authors would like to thank the industry members of the project steering group, Virgin Trains and Alstom Transport, for volunteering to run the trail and for providing advice, guidance and practical support for this project.

\section{References}

1. Bevan, A., et al., Development and validation of a wheel wear and rolling contact fatigue damage model. Wear, 2013. 307(1): p. 100-111.

2. RSSB, 'Economic Tyre Turning' on GBrailways - business case and international experience. 2014.

3. RSSB, Railway Group Standard GM/RT2466 Issue 3: Railway Wheelsets. 2010.

4. Molyneux-Berry, P. and A. Bevan, The influence of route characteristics, train design and maintenance policy on wheel tread damage, wheel life and costs for multiple-unit trains, in 17th International Wheelset Congress. 2013: Kiev, Ukraine.

5. RSSB, Cost effective turning of flange worn wheel profiles. 2007.

6. Pritchard, R., Electric multiple units. 2012: Sheffield, United Kingdom.

7. Bevan, A., P. Allen, and S. Iwnicki, Development of an anti-RCF wheel profile. 2005, Institute of Railway Research.

8. British Standards Institution, Railway applications. wheelsets and bogies. wheels. tread profile 2006, BSI.

9. Archard, J.F., Contact and rubbing of flat surfaces. Journal of Applied Physics, 1953. 24: p. 7.

10. Dirks, B. and R. Enblom, Prediction model for wheel profile wear and rolling contact fatigue. Wear, 2011. 271(1): p. 210-217.

11. Pearce, T.G. and N.D. Sherratt, Prediction of wheel profile wear. Wear, 1991. 144(1): p. 343-351. 
12. Ward, A., R. Lewis, and R.S. Dwyer-Joyce, Incorporating a railway wheel wear model into multibody simulations of wheelset dynamics, in Tribology Series, M.P.G.D. D. Dowson and A.A. Lubrecht, Editors. 2003, Elsevier. p. 367-376.

13. Jendel, T., Prediction of wheel profile wear-comparisons with field measurements. Wear, 2002. 253(1): p. 89-99.

14. Bevan, A., Wheel profile damage model - quick start guide. 2011.

15. Enblom, R. and M. Berg, Simulation of railway wheel profile development due to wear-influence of disc braking and contact environment. Wear, 2005. 258(7): p. 1055-1063.

16. Kalker, J., A fast algorithm for the simplified theory of rolling contact. Vehicle System Dynamics, 1982. 11: p. 1-13.

17. RSSB, Improving wheelset life by better understanding the causes of wheel damage. 2013.

18. Johnson, K.L., Contact mechanics. 1985, Cambridge University: UK.

19. Burstow, M., Whole life rail model application and development for RSSB - continued development of an RCF damage parameter. 2004.

20. Jacobson, B. and J.J. Kalker, Rolling contact phenomena. Vol. 411. 2000: Springer-Verlag Wien.

21. Ringsberg, J.W., et al., Prediction of fatigue crack initiation for rolling contact fatigue. International Journal of Fatigue, 2000. 22(3): p. 205-215.

22. British Standards Institution, Railway applications track rail :part 1: vignole railway rails $46 \mathrm{~kg} / \mathrm{m}$ and above. 2007, BSI. 